\title{
Implementation of health risk assessments with family health history: barriers and benefits
}

\author{
R Ryanne $\mathrm{Wu}^{1}{ }^{1}$ Lori A Orlando ${ }^{2}$
}

${ }^{1}$ Duke Center for Applied Genomics and Department of Medicine, Duke University and Health Services Research and Development, Veterans Affairs Medical Center, Durham, North Carolina, USA

${ }^{2}$ Duke Center for Applied Genomics and Department of Medicine, Duke University, Durham, North Carolina, USA

\section{Correspondence to}

Dr R Ryanne Wu, Duke Center for Applied Genomics and Department of Medicine, Duke University and Health Services Research and Development, Veterans Affairs Medical Center, 411 West Chapel Hill Street, Suite 500, Durham, NC 27701, USA; ryanne.wu@duke.edu

Received 23 April 2015 Revised 8 June 2015 Accepted 20 July 2015 Published Online First 12 August 2015

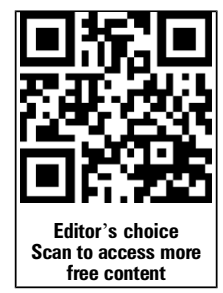

\section{ABSTRACT}

Health risk assessments provide an opportunity to emphasise health promotion and disease prevention for individuals and populations at large. A key component of health risk assessments is the detailed collection of family health history information. This information is helpful in determining risk both for common chronic conditions and more rare diseases as well. While the concept of health risk assessments has been around since the Framingham Heart Study was launched in the 1950s, and such assessments are commonly performed in the workplace today, the US healthcare system has been slow to embrace them and the emphasis on prevention that they represent. Before wider implementation of health risk assessments within healthcare can be seen, several concerns must be addressed: (1) provider impact, (2) patient impact, (3) validity of patient-entered data and (4) health outcomes effect. Here, we describe recent developments in health risk assessment design that are helping to address these issues.

\section{INTRODUCTION}

In the progression from health to disease, several transitions occur. The first is from healthy to presymptomatic, where disease is present, but the individual feels well, and is unaware of the condition. An example of this health state is the beginning of hypertension when an individual's blood pressure is elevated, but they are unaware of it. The second is from presymptomatic to disease diagnosis, and the third is from diagnosis to disease status, which can be either well controlled or uncontrolled. Health risk assessments (HRAs) are an important element of the healthy stage. The purpose of HRAs is to evaluate an individual's risk for developing common chronic diseases (see table 1 for examples), allowing clinicians to develop personalised care plans; tailoring preventive care, screening and testing to each individual's level of risk to extend health while balancing effectiveness and harms of each action with the potential risk. An example would be using an HRA to assess breast cancer risk and guide usage of breast MRI for screening. Guidelines recommend only using breast MRI in women with a certain level of risk. The goal of such efforts is to maximise benefit and minimise harm for each individual and also, when taken as a whole, for the population as well. Unfortunately, a number of constraints limit the use of HRAs in primary care, where they would be most effective. The objectives of this article are to discuss (1) the history of HRA development, (2) what the key components of HRAs are and (3) the barriers and benefits to their implementation with regard to providers, patients, data integrity and health outcomes.

\section{Origins of HRA}

In 1948, the Framingham Heart Study, an innovative longitudinal study arising from the field of epidemiology, was introduced by the Assistant Surgeon General, Joseph Mountain. The goal, as devised by the director, Thomas Dawber, was to closely follow a group of residents of Framingham, Massachusetts, using data collected to develop a risk prediction model for cardiovascular disease (CVD). ${ }^{1}$ Despite initial scepticism within academia and clinical practice, the trial was successful beyond expectations, and the field of HRA was born. In 2009, when the term 'precision medicine' was coined by Clay Christensen, he defined it as precisely predicting a medical outcome by combining a variety of data into risk algorithms. ${ }^{2}$ According to this definition, HRAs are simply the application of precision medicine to those who are healthy.

Framingham Heart Study: A long-term ongoing cardiovascular research study of the residents of the town of Framingham, Massachusetts, USA. The study began in 1948 with 5209 adult subjects, and is now on its third generation of participants. Through the study, the first HRA was developed.

Most HRAs today include the following elements: data collection (either through a web-based or paper questionnaire), risk assessment and report of risk results. For data collection, data collected depends on which conditions are included in the risk assessment. At a minimum, demographics, lifestyle, personal health history, family health history (FHH) and biometrics (such as blood pressure, weight, cholesterol, etc) are included. Other types of data, such as genetic/genomic data and individual preferences regarding comfort with risk, are just now starting to be incorporated into some models, and have the potential to refine the accuracy of risk calculations and improve shared decision making with medical providers. ${ }^{3}{ }^{4}$ The last component, the risk results report, may or may not provide guidance about how to manage your risk. Some are exceptionally detailed and even indicate how much your risk can be lowered by initiating one or more recommended preventive actions, while others merely indicate that you are at increased risk for the specified condition.

\section{The value of FHH}

$\mathrm{FHH}$, while unassuming and often disregarded, is an essential data element in HRAs. FHH is often 
Table 1 Examples of conditions for which family health history-based health risk assessment is useful

\begin{tabular}{lll}
\hline & $\begin{array}{l}\text { Risk algorithm } \\
\text { based on family } \\
\text { health history only }\end{array}$ & $\begin{array}{l}\text { Risk algorithms } \\
\text { include family } \\
\text { health history }\end{array}$ \\
\hline $\begin{array}{l}\text { Hereditary breast and ovarian } \\
\text { cancer }\end{array}$ & $\mathrm{x}$ \\
$\begin{array}{l}\text { Hereditary non-polyposis colon } \\
\text { cancer (Lynch syndrome) }\end{array}$ & $\mathrm{x}$ & \\
$\begin{array}{l}\text { Alpha-1 antitrypsin deficiency } \\
\text { Diabetes mellitus type 2 }\end{array}$ & $\mathrm{x}$ & \\
$\begin{array}{l}\text { Abdominal aortic aneurysm } \\
\text { Coronary artery disease }\end{array}$ & $\mathrm{x}$ \\
$\begin{array}{l}\text { Haemochromatosis } \\
\text { Maturity-onset diabetes of the }\end{array}$ & $\mathrm{x}$ \\
young & $\mathrm{x}$ \\
Inflammatory bowel disease & \\
$\begin{array}{l}\text { Stroke } \\
\text { Gastric cancer }\end{array}$ & $\mathrm{x}$ \\
Renal cancer & $\mathrm{x}$ \\
Age-related macular degeneration & $\mathrm{x}$ \\
\hline & $\mathrm{x}$ \\
\hline
\end{tabular}

the strongest or only predictor of disease risk (see table 1). An example of the impact of $\mathrm{FHH}$ on common disease risk is CVD, where having a parent with premature CVD increases an individual's odds of having a heart attack by $2.0 .^{5}$ While many other factors contribute to CVD risk, it is well established that patients' identify with $\mathrm{FHH}$ and that counselling regarding FHH risk has the ability to change patient behaviour. ${ }^{6-8}$

In some conditions, excluding an $\mathrm{FHH}$ can lead to missing those at highest risk for the disease. For example, many risk assessments for chronic kidney disease ask about high blood pressure and race, but do not ask about family history; however, those with autosomal dominant polycystic kidney disease, a hereditary condition that runs in families, are at the highest risk of developing chronic kidney disease even without high blood pressure. ${ }^{9}$ Endometrial cancer, a tumour of the uterus, is another example. Almost all risk assessments include exogenous oestrogen, obesity and some include family members with endometrial cancer, but most do not ask about a family history of other cancers even though endometrial cancer is part of the constellation of cancers that can occur in two hereditary cancer syndromes, Lynch syndrome and Cowden syndrome. ${ }^{10}$ While those with hereditary cancer syndromes or polycystic kidney disease are only a small proportion of those developing these two conditions, they are the ones at the highest risk of developing disease.

\section{Syndrome definitions}

Lynch syndrome: an inherited condition that increases your risk of colon cancer and other cancers. It has historically been known as hereditary non-polyposis colorectal cancer. Cowden syndrome: a disorder characterised by multiple non-cancerous tumour-like growths called hamartomas and an increased risk of developing certain cancers.

In addition to being highly predictive, risk due to $\mathrm{FHH}$ is frequently actionable. Numerous evidence-based guidelines assign the level of disease risk associated with a given combination of affected relatives, and recommend specific actions to mitigate risk. For example, the National Comprehensive Cancer Network's guidelines for breast and ovarian cancer recommend breast cancer susceptibility gene (BRCA) testing if an individual has even one family member with ovarian cancer. ${ }^{11}$ Another example is haemochromatosis. If an individual has a first-degree relative with the condition then baseline iron studies and genetic testing are recommended. ${ }^{12}$ Thus, $\mathrm{FHH}$ is the only data element that is both highly predictive and actionable in combination with other data elements and by itself.

\section{The gap in implementation}

Despite the success of the Framingham Heart Study, further development and implementation of HRAs gained little traction until an HRA developed by the Center for Disease Control (CDC) was made publicly available in $1980 .^{13}$ Incidentally, the 1980s were also a time when rapidly increasing healthcare costs were becoming a problem for employers and insurers. HRAs were seen as a way to manage these costs. ${ }^{14}$ Through further collaborative effort by Prudential and the CDC, they demonstrated that HRAs could ultimately lower company healthcare expenditures, as well as reduce absenteeism and increase productivity. ${ }^{15} 16$ These findings and Prudential's takeover of the CDC programme in 1986 led to rapid uptake among US employers and insurance companies; however, uptake continued to be anaemic in the healthcare setting. ${ }^{13}$

There are several explanations for why implementation in the healthcare system failed to take root. The current structure of healthcare in the United States has led to a disconnect between public health and healthcare, increasing demands on primary care providers and a perverse incentive system that rewards aggressive disease treatment over the maintenance of health. ${ }^{13} 17$ This combination of features encouraged the development of a healthcare system incapable of responding to the needs of the healthy segment of the population due to a vicious cycle dominated by sick patients getting sicker, less time to address prevention among healthy patients and ultimately healthy patients getting sick. ${ }^{18}$ Given this environment, it is understandable that uptake of HRAs in clinical practice was slow.

Fortunately, these barriers to prevention have been highlighted in recent studies, and their unsustainable impact on the US healthcare system has been recognised. In particular, the five Mirror, Mirror studies performed by the Commonwealth Fund, which assessed cost and quality of healthcare in 11 international healthcare systems between 2004 and 2014, ranked the USA last in quality and highest in expenditures, and showed that there had been little improvement over the 10 -year period. ${ }^{19}$ In addition, the Affordable Care Act (ACA) of 2010 has stressed the need for improving quality of care, emphasising prevention and lowering costs. HRAs have been recognised as valuable assets to reaching these objectives and integral tools for redesigning healthcare systems. Through the ACA, Medicare beneficiaries are now provided free annual wellness examinations that include an HRA. That being said, widespread implementation of HRAs in primary care still has many practical impediments that need to be addressed: minimisation of provider burden, ease of use for patients, data quality (particularly $\mathrm{FHH}$ data) and clinical effectiveness in primary care populations. Each of these is described in detail below.

\section{BARRIERS AND BENEFITS Impact on providers}

Providers, primary care providers in particular, routinely face the challenge of balancing health maintenance and disease 
prevention issues, which are of longer lasting significance, with concerns that may be of higher acuity, but less long-term import. With face times shrinking to just over 9 min for most appointments, the tyranny of the urgent often wins out. ${ }^{18}$ In addition, because the steps involved in HRAs (ie, data collection, risk calculation and evidence synthesis) are complex and time consuming, integration into normal work flow can be challenging. ${ }^{20}$ Risk algorithms are often more complex than can be done manually, and the calculators for each condition are typically found in various places across the web, and most are not integrated into electronic medical record systems. In addition, producing an actionable risk management plan is difficult in the face of the magnitude of literature available. Efforts to foster discussion with providers around these topics have not been successful due to many of the same reasons that implementing HRAs has lagged. ${ }^{21}$

The rapidly developing field of health information technology (IT) may offer one solution to these complex and inter-related barriers. Patient-facing web-based or computer-based HRA tools can: transfer the data collection component from the clinical setting to the patient's home, and provide algorithm-based risk calculations and discreet actionable steps as part of the risk management plan for the provider at the point of care. Several such FHH-based HRA tools have been built with these capabilities. ${ }^{22}$ Table 2 gives examples of currently available tools and their characteristics.

Uptake of these tools has been anecdotally promising. Currently, there is only one published study that reports physician experience with and uptake of an HRA tool. That study reported that primary care providers felt the HRA tool tested was easy to incorporate into workflow (100\%), improved their quality of care $(85 \%)$, made their practice easier $(75 \%)$ and enhanced their understanding of the importance of $\mathrm{FHH}$
$(62 \%) .^{23}$ These results suggest that with the right combination of features, electronic HRA tools can be accepted and valued by busy primary care clinicians.

\section{Impact on patients}

If patient-facing tools were taken up by primary care providers, some have raised concern that patients do not have the IT know-how to use these tools or the inclination to do so. Current trends in patient usage of the internet to inform health do not support this view. Millions of patients use the internet on a daily basis to better understand their health. ${ }^{24} 25$ Even among minorities and those with household incomes of \$25 000-\$50 000 per year, internet use is over $66 \% .^{26}$ In addition, individuals recognise the value of $\mathrm{FHH}$ with over $90 \%$ of Americans surveyed reporting that their personal health is impacted by their FHH. ${ }^{27}{ }^{28}$ When health systems place HRAs on their patient portals, significant uptake occurs. For example, the Northshore University Health System launched Health Heritage on their health portal in May 2014, and 500 patients completed the assessment within the first 30 days (unpublished data, Lori Orlando, 2015). This was without any organised plan by the health system to notify patients to the availability of the tool.

There are also concerns of racial and socioeconomic discrimination as those of lower socioeconomic status may not have the IT mastery or access required to complete such tools. In fact, HRA tools can potentially reduce health disparities. Algorithm-based risk assessment is not susceptible to the subconscious biases that providers may bring to the patient encounter. In implementation studies of HRA tools, these disparities have also not borne out with no difference in uptake based on education level or race, two significant risk factors for healthcare disparity. ${ }^{23}{ }^{29}$ Patients using one HRA tool, MeTree, reported that the tool was easy to use (94\%) and understand

Table 2 Examples of patient-facing electronic family health history-based health risk assessment tools

\begin{tabular}{|c|c|c|c|c|c|c|}
\hline Programme & Decision support diseases & Completed by & $\begin{array}{l}\text { Publicly } \\
\text { available }\end{array}$ & $\begin{array}{l}\text { Who receives } \\
\text { output }\end{array}$ & $\begin{array}{l}\text { Available at } \\
\text { point of care }\end{array}$ & $\begin{array}{l}\text { Action-oriented } \\
\text { recommendation }\end{array}$ \\
\hline MeTree & $\begin{array}{l}\text { Colon, breast and ovarian cancer; aortic aneurysm, } \\
\text { heart disease, stroke, diabetes, hereditary cancer } \\
\text { syndrome, hereditary cardiovascular syndrome, } \\
\text { hereditary liver diseases }\end{array}$ & Patient online & In future & $\begin{array}{l}\text { Patient and } \\
\text { physician }\end{array}$ & Yes & Yes \\
\hline Schroy et al & Colon cancer & Physician & Unknown & Physician & Yes & No \\
\hline GRACE & Breast cancer & $\begin{array}{l}\text { Patient in physician's } \\
\text { office }\end{array}$ & Unknown & $\begin{array}{l}\text { Patient, clinical } \\
\text { nurse specialist, } \\
\text { physician }\end{array}$ & Yes & No \\
\hline $\begin{array}{l}\text { Family } \\
\text { Healthware }\end{array}$ & $\begin{array}{l}\text { Coronary heart disease, diabetes, stroke, colon, } \\
\text { breast and ovarian cancer }\end{array}$ & Patient online & No & Patient & No & No \\
\hline $\begin{array}{l}\text { Family } \\
\text { HealthLink }\end{array}$ & Coronary heart disease, cancer & Patient online & Yes & Patient & No & No \\
\hline CRIS & Colon cancer & $\begin{array}{l}\text { Patient in physician's } \\
\text { office }\end{array}$ & No & $\begin{array}{l}\text { Patient and } \\
\text { physician }\end{array}$ & Yes & No \\
\hline MyGenerations & Cancer & Patient online & Yes & Patient & No & No \\
\hline $\begin{array}{l}\text { Hughes } \\
\text { RiskApps }\end{array}$ & $\begin{array}{l}\text { Breast and ovarian cancer, colon cancer, } \\
\text { hereditary cancer risk }\end{array}$ & $\begin{array}{l}\text { Patient-clinician can } \\
\text { revise online or } \\
\text { physician's office }\end{array}$ & Yes & $\begin{array}{l}\text { Patient and } \\
\text { physician }\end{array}$ & Yes & No \\
\hline $\begin{array}{l}\text { HealthHeritage. } \\
\text { net }\end{array}$ & $\begin{array}{l}87 \text { diseases: multiple cancers, diabetes, } \\
\text { neuromuscular diseases and cardiovascular } \\
\text { diseases }\end{array}$ & Patient online & In future & Patient & No & No \\
\hline Invitae & $\begin{array}{l}\text { Cardiac disease, colon cancer, Charcot-Marie- } \\
\text { Tooth, breast cancer, pancreatic cancer }\end{array}$ & Physician online & Yes & $\begin{array}{l}\text { Patient and } \\
\text { physician }\end{array}$ & ? & No \\
\hline MyFamily & $\begin{array}{l}\text { Cancer, cardiology, gastrointestinal } \\
\text { proprietary algorithms }\end{array}$ & Patient & In future & Physician & Yes & Yes \\
\hline Myriad & 29 cancers & Patient & Yes & Patient & No & No \\
\hline Power Lineage & Cancer & Patient and physician & Yes & Physician & No & No \\
\hline
\end{tabular}


$(97 \%)$ irrespective of education level or race. ${ }^{23}$ For what barriers do exist regarding access to such tools, much work is beginning to be done in the use of mobile technologies to address these issues. ${ }^{30} 31$

When patient-facing HRA IT tools are used, patient reactions are overwhelmingly positive. Participants in three studies of HRA tools reported being generally satisfied with their experience (83\%-90\%), that completing the tool did not cause persistent anxiety (96\%) and that they would recommend it to others (93\%-99\%). ${ }^{23} 2932$ In addition to use of the tool itself being a positive experience, there are additional benefits to the patient of: increased understanding about their risk for disease and the ways to mitigate their risk and more nuanced engagement in their health with the potential for enhanced shared decision making between patients and providers. ${ }^{3} 4$

\section{Validity of patient-entered data}

Concerns have been raised about the reliability of patiententered data outside the setting of the clinical encounter. In particular, there are concerns about the accuracy of the $\mathrm{FHH}$ collected. Questions arise around differentiation of a primary cancer versus metastatic cancer, different types of CVD such as coronary artery disease versus valvular conditions and diseases with names that sound similar such as inflammatory bowel disease and irritable bowel disease. In a systematic review of family history questionnaires, strong agreement (70\%-100\%) was found between patient-entered data and the presumed gold standard of genetic counsellor-acquired data. ${ }^{33}$ In comparison with what is typically collected in routine practice, patiententered data are significantly superior. ${ }^{20} 293334$ In the evaluation of MeTree, less than 4\% of patients' medical records prior to the HRA implementation contained high-quality family history information documented for even one relative. ${ }^{35}$ With the use of MeTree, $>99 \%$ of family history data entered by patients had at least one relative with high-quality family history information, and over $50 \%$ of pedigrees had at least $50 \%$ of relatives with high-quality information. ${ }^{36}$

When patients are offered education and the opportunity to discuss their $\mathrm{FHH}$ with relatives, even further improvements in accuracy and comprehensiveness can be seen. ${ }^{37}$ Understanding the essential elements of a quality $\mathrm{FHH}$ and using that information to guide discussions with family members results in almost half of patients providing new or updated information and a change in recommendations for disease risk management for $16 \%$ of patients. $^{38}$

\section{Do HRA tools improve clinical care?}

Patient and provider barriers addressed, impact on outcomes must still be shown. A considerable number of guidelines tailor recommended risk management strategies to an individual's risk for disease, and HRAs offer the ability to bring the guidelines for various conditions together into one succinct, but comprehensive, report. Screening strategies recommended for higher risk individuals have a greater sensitivity than population-based screening approaches, but are also typically associated with higher costs or greater potential adverse events that warrant limiting them to those at the highest level of disease risk. This approach of tailored risk management helps to balance benefits and harms for the individual patient and when assessed at the population level helps identify those at higher risk and minimise overuse among those at average risk. To show that HRAs are, in fact, able to increase uptake of these guidelines and improve individual/population health, they need to be able to: improve identification of individuals at increased disease risk, increase the match between risk level and risk-management strategy and improve patient acceptance of management recommendations above what is currently occurring in routine care.

Surveys of providers have shown that physicians do not feel confident in their comprehension of the guidelines regarding risk, and frequently overestimate or underestimate the risk. ${ }^{39-42}$ Fortunately, several studies have shown that FHH-based HRAs can accurately estimate risk, and identify a significant number of patients who were not identified during routine visits with their providers. ${ }^{34} 43$ For example, the Family Healthware trial found that $82 \%$ of participants were at strong or moderate risk for at least one of six conditions; ${ }^{44}$ the Health Heritage trial found $42 \%$ to be at increased risk ${ }^{29}$ and the MeTree study found $44 \%$ to be at increased risk. ${ }^{45}$

While numerous studies have shown that HRAs can improve discrimination between average-risk and high-risk individuals, less has been published regarding the impact on behaviour of providers and patients as a result of this risk information. Results regarding the HRA tool, MeTree, showed decreased overuse of high-risk services among average-risk individuals by $81 \%$ while increasing use among appropriate high-risk individuals (unpublished data, Lori Orlando, 2015). In another study, a significant increase in referrals to genetic services was seen with the implementation of a breast cancer risk assessment tool, Hughes RiskApps. ${ }^{46}$ Quereshi et $a l^{43}$ showed significant improvements in smoking cessation rates with use of a $\mathrm{FHH}$-focused HRA. These findings, showing the value of $\mathrm{FHH}$ usage, have been borne out through other studies as well. ${ }^{6} 47$ Trials are ongoing to better understand how to engage patients and providers in shared decision making surrounding patients' behavioural and psychosocial risks. ${ }^{4}$ Further work needs to be done in this area to better understand the impact of HRAs on patient and provider behaviour as it relates to screening. ${ }^{48}$

\section{CONCLUSION}

HRAs, a precision medicine tool intended to be used by healthy patients, hold promise for the enhancement of preventive care by improving both individual health and population health through accurate estimation of risk for disease and improvement of the match between risk level and risk-management strategy. HRA tools may also enhance patient experiences by increasing patient activation and shared decision making, thereby incorporating patient values into the patient-provider encounter and improving adherence to recommendations. HRAs' accuracy in assigning risk can be further improved as more structured $\mathrm{FHH}$ data are collected and analysed to understand the true risk conveyed by familial illness. Just as the National Institutes of Health is encouraging data sharing among randomised controlled trials, similar efforts are needed between large structured $\mathrm{FHH}$ databases so that guidelines can be further refined to reflect the true risk associated with a family history of various conditions.

Furthermore, enhancement of such tools' accuracy and effectiveness may be achieved by combining genetic and genomic data about disease risk into current risk algorithms. While uptake of patient-facing HRAs has been slow to start in the US healthcare system, they are beginning to gain traction as the evidence base builds and innovations in health IT allow improved incorporation into clinical workflow. HRA is one of the few precision medicine tools that is ready for immediate translation into clinical care (especially primary care) and as such can pave the way for translation of other genomic and personalised medicine advances in these fields by increasing clinicians' familiarity with these types of tools and their benefits. 


\section{Main messages}

- Family health history $(\mathrm{FHH})$ is an essential element of health risk assessment (HRA).

- HRAs document FHH better than is done in routine practice.

- HRAs identify a significant number of patients who have above-average risk for specific conditions.

\section{Current research questions}

What is the role of health risk assessments in the continuum of care?

- What are the potential barriers to implementation of health risk assessment tools?

- How does implementation of health risk assessment tools impact population health?

\section{Key references}

- Dawber TR, Meadors GF, Moore FE Jr. Epidemiological approaches to heart disease: the Framingham Study. Am J Public Health 1951;41:279-81.

- Goetzel RZ, Staley P, Ogden L, et al. A framework for patient-centered health risk assessments_-providing health promotion and disease prevention services to Medicare beneficiaries. Atlanta, GA: US Department of Health and Human Services; Centers for Disease Control and Prevention, 2011.

- Barrison AF, Smith C, Oviedo J, et al. Colorectal cancer screening and familial risk: a survey of internal medicine residents' knowledge and practice patterns. Am J Gastroenterol 2003;98:1410-16.

- Orlando LA, Wu RR, Beadles C, et al. Implementing family health history risk stratification in primary care: impact of guideline criteria on populations and resource demand. Am J Med Gen C Semin Med Genet 2014;166C:24-33.

- Qureshi N, Wilson B, Santaguida P, et al. Family history and improving health. Evid Rep Technol Assess 2009:1-135.

\section{Self assessment questions}

Please answer true or false for the below statements:

1. Health risk assessments (HRAs) benefit patients during the symptomatic stage of disease.

2. The Framingham Heart Study developed the first risk prediction model in the USA

3. HRAs were first and most successfully taken up by employers and insurance companies.

4. All HRAs provide clinical decision support.

5. HRAs can have impact at a population level.

Contributors RRW wrote the initial draft of the manuscript. LAO critically revised the manuscript. Both contributed equally to overall outline of paper content.
Disclaimer The views expressed in this article are those of the authors, and do not necessarily reflect the position or policy of the Department of Veterans Affairs or the US government.

Competing interests RRW is an employee of the Department of Veterans Affairs of the USA. No author received compensation for preparation of this manuscript apart from his or her employment. LAO and RRW report that they are leading the research and development of the web-based health risk assessment tool, MeTree.

Provenance and peer review Commissioned; externally peer reviewed.

Data sharing statement Further information on unpublished data pertaining to publications is available to other researchers upon request by emailing the corresponding author.

\section{REFERENCES}

1 Dawber TR, Meadors GF, Moore FE Jr. Epidemiological approaches to heart disease: the Framingham Study. Am J Public Health Nations Health 1951:41:279-81.

2 Christensen CM, Grossman JH, Hwang J. The innovator's prescription: a disruptive solution for health care. New York: McGraw-Hill, 2009.

3 Glasgow RE, Dickinson P, Fisher L, et al. Use of RE-AIM to develop a multi-media facilitation tool for the patient-centered medical home. Implement Sci 2011;6:118

4 Krist AH, Glenn BA, Glasgow RE, et al. Designing a valid randomized pragmatic primary care implementation trial: the my own health report (MOHR) project. Implement Sci 2013;8:73.

5 Roger VL, Go AS, Lloyd-Jones DM, et al. Heart disease and stroke statistics--2012 update: a report from the American Heart Association. Circulation 2012;125: e2-e220.

6 Murabito JM, Evans JC, Larson MG, et al. Family breast cancer history and mammography: Framingham Offspring Study. Am J Epidemiol 2001;154:916-23.

7 Hariri S, Yoon PW, Qureshi N, et al. Family history of type 2 diabetes: a population-based screening tool for prevention? Genet Med 2006:8:102-8.

8 Pijl M, Timmermans DR, Claassen L, et al. Impact of communicating familial risk of diabetes on illness perceptions and self-reported behavioral outcomes: a randomized controlled trial. Diabetes Care 2009;32:597-9.

9 Hildebrandt F. Genetic kidney diseases. Lancet 2010;375:1287-95.

10 Burke WM, Orr J, Leitao M, et al., SGO Clinical Practice Endometrial Cancer Working Group. Endometrial cancer: a review and current management strategies: part I. Gynecol Oncol 2014;134:385-92.

11 Daly MB, Pilarski R, Axilbund JE, et al. Genetic/familial high-risk assessment: breast and ovarian, version 1.2014. J Natl Compr Canc Netw 2014;12:1326-38.

12 El-Serag HB, Inadomi JM, Kowdley KV. Screening for hereditary hemochromatosis in siblings and children of affected patients. A cost-effectiveness analysis. Ann Intern Med 2000;132:261-9.

13 Goetzel RZ, Staley P, Ogden L, et al. A framework for patient-centered health risk assessments-providing health promotion and disease prevention services to Medicare benificiaries. Atlanta, GA: US Department of Health and Human Services; Centers for Disease Control and Prevention, 2011.

14 Breslow L, Fielding J, Herrman AA, et al. Worksite health promotion: its evolution and the Johnson \& Johnson experience. Preve Med 1990;19:13-21.

15 DeFriese GH, Fielding JE. Health risk appraisal in the 1990s: opportunities, challenges, and expectations. Ann Rev Public Health 1990:11:401-18.

16 Loeppke R, Nicholson S, Taitel M, et al. The impact of an integrated population health enhancement and disease management program on employee health risk, health conditions, and productivity. Popul Health Manag 2008;11:287-96.

17 McGinnis JM, Williams-Russo P, Knickman JR. The case for more active policy attention to health promotion. Health Aff 2002;21:78-93.

18 Stange KC, Zyzanski SJ, Jaen CR, et al. Illuminating the 'black box'. A description of 4454 patient visits to 138 family physicians. J Fam Pract 1998;46:377-89.

19 Davis K, Stremikis K, Schoen C, et al. Mirror, mirror on the wall, 2014 update: how the US Healthcare System Compares Internationally. The Commonwealth Fund.

20 Sweet KM, Bradley TL, Westman JA. Identification and referral of families at high risk for cancer susceptibility. J Clin Oncol 2002;20:528-37.

21 Schroy PC III, Glick JT, Geller AC, et al. A novel educational strategy to enhance internal medicine residents' familial colorectal cancer knowledge and risk assessment skills. Am J Gastroenterol 2005;100:677-84.

22 Orlando LA, Buchanan AH, Hahn SE, et al. Development and validation of a Primary Care-based family health history and decision support program (MeTree@). NCMJ 2013;74:287-96.

23 Wu RR, Orlando LA, Himmel TL, et al. Patient and primary care provider experience using a family health history collection, risk stratification, and clinical decision support tool: a type 2 hybrid controlled implementation-effectiveness trial. BMC Fam Pract 2013;14:111.

24 Fox S, Duggan M. Health Online 2013: A Project of the Pew Research Center. Secondary Health Online 2013: A Project of the Pew Research Center 2013. http:/l www. pewinternet.org/2013/01/15/health-online-2013/

25 Bansil P, Keenan NL, Zlot Al, et al. Health-related information on the Web: results from the HealthStyles Survey, 2002-2003. Prev Chronic Dis 2006;3:A36. 
26 File T, Ryan C. Computer and Internet Use in the United States: 2013. Secondary Computer and Internet Use in the United States: 2013, 2014. http://www.census. gov/content/dam/Census/library/publications/2014/acs/acs-28.pdf

27 Foland J, Burke B. Family Health History data collection in Connecticut. Hartford, CT: Connecticut Department of Public Health, Genomics Office, Feb 2014.

28 Centers for Disease C, Prevention. Awareness of family health history as a risk factor for disease-United States, 2004. MMWR Morb Mortal Wkly Rep 2004;53:1044-7.

29 Cohn WF, Ropka ME, Pelletier SL, et al. Health Heritage(c) a web-based tool for the collection and assessment of family health history: initial user experience and analytic validity. Public Health Genomics 2010;13:477-91.

30 Beratarrechea A, Lee AG, Willner JM, et al. The impact of mobile health interventions on chronic disease outcomes in developing countries: a systematic review. Telemed J E Health 2014;20:75-82.

31 Broderick A, Haque F. Mobile Health and Patient Engagement in the Safety Net: A Survey of Community Health Centers and Clinics. Secondary Mobile Health and Patient Engagement in the Safety Net: A Survey of Community Health Centers and Clinics May 13 2015. http://www.commonwealthfund.org/publications/issue-briefs/ 2015/may/mobile-health-and-patient-engagement-in-the-safety-net

32 Qureshi N, Standen PJ, Hapgood R, et al. A randomized controlled trial to assess the psychological impact of a family history screening questionnaire in general practice. Fam Pract 2001;18:78-83.

33 Reid GT, Walter FM, Brisbane JM, et al. Family history questionnaires designed for clinical use: a systematic review. Public Health Genomics 2009;12:73-83.

34 Frezzo TM, Rubinstein WS, Dunham $D$, et al. The genetic family history as a risk assessment tool in internal medicine. Genet Med 2003;5:84-91.

35 Powell KP, Christianson CA, Hahn SE, et al. Collection of family health history for assessment of chronic disease risk in primary care. NCMJ 2013;74:279-86.

36 Wu RR, Himmel TL, Buchanan AH, et al. Quality of family history collection with use of a patient facing family history assessment tool. BMC Fam Pract 2014;15:31.

37 Tehranifar $\mathrm{P}, \mathrm{Wu}$ HC, Shriver T, et al. Validation of family cancer history data in high-risk families: the influence of cancer site, ethnicity, kinship degree, and multiple family reporters. Am J Epidemiol 2015;181:204-12.

38 Beadles CA, Ryanne Wu R, Himmel T, et al. Providing patient education: impact on quantity and quality of family health history collection. Fam Cancer 2014;13:325-32

39 Baldwin LM, Trivers KF, Andrilla CH, et al. Accuracy of ovarian and colon cancer risk assessments by U.S. physicians. J Gen Intern Med 2014;29:741-9.
40 Acton RT, Burst NM, Casebeer L, et al. Knowledge, attitudes, and behaviors of Alabama's primary care physicians regarding cancer genetics. Acad Med 2000;75:850-2.

41 Barrison AF, Smith C, Oviedo J, et al. Colorectal cancer screening and familial risk: a survey of internal medicine residents' knowledge and practice patterns. Am J Gastroenterol 2003;98:1410-16.

42 Gramling R, Nash J, Siren K, et al. Family physician self-efficacy with screening for inherited cancer risk. Ann Fam Med 2004;2:130-2.

43 Qureshi N, Armstrong S, Dhiman P, et al. Effect of adding systematic family history enquiry to cardiovascular disease risk assessment in primary care: a matched-pair, cluster randomized trial. Ann Intern Med 2012;156:253-62.

44 O'Neill SM, Rubinstein WS, Wang C, et al. Familial risk for common diseases in primary care: the Family Healthware Impact Trial. Am J Prev Med 2009;36:506-14.

45 Orlando LA, Wu RR, Beadles C, et al. Implementing family health history risk stratification in primary care: impact of guideline criteria on populations and resource demand. Am J Med Genet C Semin Med Genet 2014;166C:24-33.

46 Ozanne EM, Loberg A, Hughes $S$, et al. Identification and management of women at high risk for hereditary breast/ovarian cancer syndrome. Breast J 2009;15:155-62.

47 Codori AM, Petersen GM, Miglioretti DL, et al. Health beliefs and endoscopic screening for colorectal cancer: potential for cancer prevention. Prev Med 2001; 33(2 Pt 1):128-36.

48 Qureshi N, Wilson B, Santaguida P, et al. Family history and improving health. Evid Rep Technol Assess (Full Rep) 2009;186:1-135.

\section{Answers}

1. False

2. True

3. True

4. False

5. True 